\title{
ARQUITECTURA Y RETABLÍSTICA NOVOHISPANA: LAS OBRAS DE FELIPE DE UREÑA EN OAXACA
}

\author{
POR \\ FÁTIMA HALCON \\ Dra. por la Universidad de Sevilla
}

\begin{abstract}
This article analyzes and gives unpublished documents about the convents of the Seven Princes and San Francisco of Oaxaca (Mexico) whose author is the architec Felipe de Ureña, one of the most representative artist of the eighteen century in New Spain.
\end{abstract}

Felipe de Ureña fue uno de los arquitectos-retablistas más importantes dentro del panorama artístico novohispano del setecientos que adoptó la nueva estética arquitectónica introducida por Jerónimo de Balbás en 1720. Si Balbás fue el protagonista indiscutible de la revolución de las formas al implantar el soporte estípite a escala gigantesca como parte principal del orden arquitectónico, no es menos cierto que Ildefonso Iniesta Bejarano, Miguel Custodio Durán y Felipe de Ureña fueron los tres artistas mexicanos más importantes y novedosos que siguieron al maestro castellano en la evolución del arte y propagaron el empleo del estípite por gran parte del territorio nacional. Ureña comienza su actividad artística como maestro ensamblador en la ciudad de México y sus alrededores; más tarde aparece como arquitecto en tierras centrales y norteñas y por último lo encontramos en la ciudad de Oaxaca donde trabajará en dos importante obras como arquitecto y entallador: el convento de los Siete Príncipes y el convento de San Francisco. A lo largo de su dilatada vida desarrollará una actividad trashumante que le servirá de acicate para la propagación de unas ideas nuevas llenas de originalidad y plenas de dinamismo barroco con el empleo de la columna estípite como baluarte de las nuevas formas.

Todavía está por hacer una monografía sobre Felipe de Ureña si bien se conocen algunos datos de interés sobre sus actividades. Manuel Toussaint lo identifica junto con sus hermanos, José, Carlos e Hipólito como los autores del retablo dedicado a Santiago en la Capilla del Tercer Orden de San Francisco de México y los retablos y la mesa central para la sacristía de San Francisco en Toluca, obras de 1729 y que considera de "un churriguera indiscutible» ${ }^{1}$ Los recientes trabajos de Guillermo Tovar han demostrado que en 1741 contrata para la ciudad de México el retablo mayor de la iglesia del Carmen y un año más tarde dos colaterales para el coro

1 Toussaint, Manuel: Arte Colonial en México. Unam. Instituto de Investigaciones Estéticas. México, 1990, pág. 180. 
de la capilla del Tercer Orden de San Francisco así como la obligación para fabricar en 1744 el retablo mayor de la iglesia de Texcoco ${ }^{2}$.

Aunque en sus comienzos se dedicó al arte del ensamblaje a partir de la década de los cincuenta se encuentra plenamente incorporado a las actividades arquitectónicas hasta el punto de ser nombrado maestro mayor de la ciudad de Guanajuato en $1756^{3}$. Su gran intervención como arquitecto la realizó para la iglesia de la Compañía de Guanajuato (1755-1783) que junto al sagrario metropolitano fueron las primeras iglesias en donde se utilizó el estípite en el exterior. En Guanajuato empleó el estípite como soporte y orden arquitectónico desarrollándose su influencia por toda la reglón norteña como puede apreciarse en el templo de Guadalupe de Aguascalientes donde se identifica su autoría así como en otras iglesias de la zona ${ }^{4}$. En Oaxaca está a partir de 1766-67, constituyendo la primera noticia en la ciudad el reconocimiento de los terrenos donde se hallaba edificada la iglesia del Patrocinio para dar su parecer sobre la conveniencia del lugar como futura sede del convento de indias cacicas que pensaba edificarse 5 .

Desde que Alonso García Bravo trazara la ciudad de Oaxaca se establecieron una serie de premisas para su posterior desarrollo ${ }^{6}$. Entre otras la construcción de conventos para las distintas órdenes religiosas que llegaron con los conquistadores: dominicos, franciscanos y agustinos, También se determinaron los lugares destinados a iglesias y ermitas que servían para el culto de los nuevos cristianos. Una de las iglesias que se levantaron en las postrimerías del xvi fue la de Los Siete Príncipes, alejada del centro de la ciudad y situada en un barrio que, todavía en el siglo XVIII, conservaba una población eminentemente indígena 7 . En estos conventos habitaron los religiosos venidos de España pero pronto comenzaron nuevas vocaciones de personas nacidas en la Nueva España, descendientes directos de los primeros conquistadores, sin que se admitiesen mestizos ni indios puros.

A partir de la Real Cédula de 26 de Marzo de 1697 por la que se ordenaba que las mestizas que quisieran ser religiosas se les admitiese en los monasterios y que los indios podían acceder a los puestos eclesiásticos comenzaron las solicitudes de permisos tanto a la Curia eclesiástica como al Rey con el fin de construir conventos para este fin. En esta Cédula se hacía una clara distinción entre indio y mestizo, considerándose los primeros como los descendientes de los indios principales llamados "caciques», los cuales debían tener «todas las preeminencias y honores que se acostumbraba conferir a los nobles hijosdalgo de Castilla, guardándoles en lo posible sus antiguos fueros o privilegios» 8 . Desde entonces se comenzaron los trámites para la fundación de un convento de indias cacicas en la ciudad de México consultándose al Consejo de Indias en 1733 y dándose el consentimiento en el mismo año. Se fundó bajo la advocación del Corpus Christi una comunidad de capuchinas por considerase esta orden religiosa la que congeniaba más con el espíritu indígena porque «andan descalzas, no visten lienzo, ayunan de continuo, rara vez comen carne, duermen en una estera, observan en mayor recogimiento en sus chozas y profesan la mayor pobreza y obediencian ${ }^{9}$.

El 13 de Mayo de 1743, D. Manuel de Velasco Aguilar y D. Joseph López de Chaves, caci-

2 Tovar y de Teresa, Guillermo: México Barroco. México, 1981, pág. 331.

3 Bérchez, Joaquín: Arquitectura mexicana de los siglos XVII y XXVIII. Grupo Azabache. México, 1992, pág. 266.

4 Tovar y de Teresa, Guillermo: op. cit., pág. 88.

5 AGI. México 2661. 24 de Septiembre de 1766.

6 Ramirez Bohórouez, Everardo: Itinerario crítico de mi ciudad: Oaxaca.. H. Ayuntamiento Constitucional 1986-89. Oaxaca, 1980 , págs. 15-16.

7 Castañeda Guzmán, Luis: Templo de los Príncipes y Monasterios de Nuestra Señora de los Angeles. Instituto Oaxaqueño de las Culturas. México, 1993, pág. 14.

8 Konetzke, Richard: Historia de la formación social de Hispanoamérica 1493-1810. Vol. III. Primer Tomo (16911770). C.S.I.C., Madrid, 1962. pág. 67.

9 Idem., pág. 212. 
ques del Valle de Oaxaca, presentaron ante el Deán y Cabildo de la Diócesis su aspiración de fundar y edificar un convento de monjas para las hijas de los caciques, descendientes de la Gentilidad,» sin mezcla de infección u otra secta reprobada a semejanza de la limpieza de sangre de los reinos castellanos" ${ }^{10}$. El convento albergaría treinta y tres religiosas, seguiría las reglas de las capuchinas y se mantendría con la limosna de los fieles. Su fundamento fue servir a Dios pero también estaría apoyado en el estudio, adelantamiento y aplicación del idioma castellano. Se tomaría de modelo las recientes fundaciones de los conventos de México y Valladolid, considerándose que Oaxaca, al ser provincia rica, produciría limosna suficiente para el mantenimiento de las monjas. Para evitar rivalidades posteriores se consultó con otras comunidades religiosas existentes en Oaxaca las cuales no pusieron ningún impedimiento a la nueva fundación (Fig. 1).

El Obispo mandó señalar un sitio para el convento indicando ser el más conveniente los alrededores de la iglesia llamada de la Preciosísima Sangre de Cristo, fundada por don Lorenzo de Olivera Avila con tres fines: que se venerase perpetuamente el Stmo. Sacramento, que su pavimento sirviese de sepultura a los pobres y que se enterrasen los miembros del Patronato bajo la bóveda del altar mayor. La fundación de esta iglesia estaba unida a un vínculo, anexo al Patronato, compuesto de diferentes fincas y posesiones pero gravado con varios censos de capellanías y otras obras piadosas. A los nueve años de la fundación del vínculo sus sucesores Da Juana de Olivera y su hijo D. Tomás de Llano renunciaron públicamente al mismo, vendiéndose en almoneda el trapiche de Santa Tecla, su principal inmueble, sucediendo lo mismo en 1738 con las casas principales de la fundación, sin que quedasen cubiertas las deudas. Años más tarde, los sucesores renunciaron a su derecho y al estar libre motivó que los caciques realizaran los trámites pertinentes para establecer el convento en aquel lugar.

El 17 de marzo de 1767, el Obispo da la licencia y el permiso para la fundación mediante la cual los caciques se obligaban a labrar y a adornar el futuro convento a su costa. Se solicitó el permiso del Rey y se nombró una persona intermediaria entre el Obispado y Ayuntamiento para cobrar y percibir el dinero y las limosnas destinados al mantenimientos de las monjas, quedando sujeto el monasterio al Prelado Diocesano. La solicitud manifestaba que existía cierto inconveniente para instalarse en la iglesia de la Sangre de Cristo y las casas adyacentes que había ofrecido Doña Petronia Latatua, heredera del vínculo, por temor a futuros pleitos con sus sucesores que considerasen un incumplimiento en los requisitos de la fundación del mismo. Ante estos problemas, los caciques comienzan a buscar un lugar más seguro, sano y proporcionado para sus religiosas.

El Rey se comprometió a donar dos mil pesos para ayuda de la fábrica del convento pero los caciques no tenían posibles para una edificación entera de nueva planta por lo que se consideró propicia la iglesia de Nuestra Señora del Patrocinio. Ante tal incertidumbre se pide la opinión sobre el lugar a un maestro de arquitectura y a algunos médicos. Felipe de Ureña emite un informe aconsejando buscar otro emplazamiento por estar enclavada la iglesia del Patrocinio en un paraje húmedo de tierra barrosa, poco saludable y sujeto a aires contaminados ${ }^{11}$. El obispo de Oaxaca D. José Gregorio de Ortigosa propuso utilizar la iglesia de los Siete Principes como sede conventual, libre de todo uso y vínculos, por hallarse situada dentro de un barrio eminentemente indígena, alejada del centro de la ciudad y ser lugar saludable e idóneo para la fundación de un convento ${ }^{12}$. Se solicita de nuevo a Felipe de Ureña que examine el solar de los Siete Príncipes. Junto con el maestro de arquitectura José Vicente Cortés emiten un informe sobre la idoneidad del lugar por «tener ciento doce varas de Norte a Sur y de fondo cien varas de Oriente a Ponien-

\footnotetext{
10 AGI. México 2661. 24 de Septiembre de 1767.

11 Idem.

12 Castañeda Guzmán, Luis: Op. cit., pág. 22.
} 

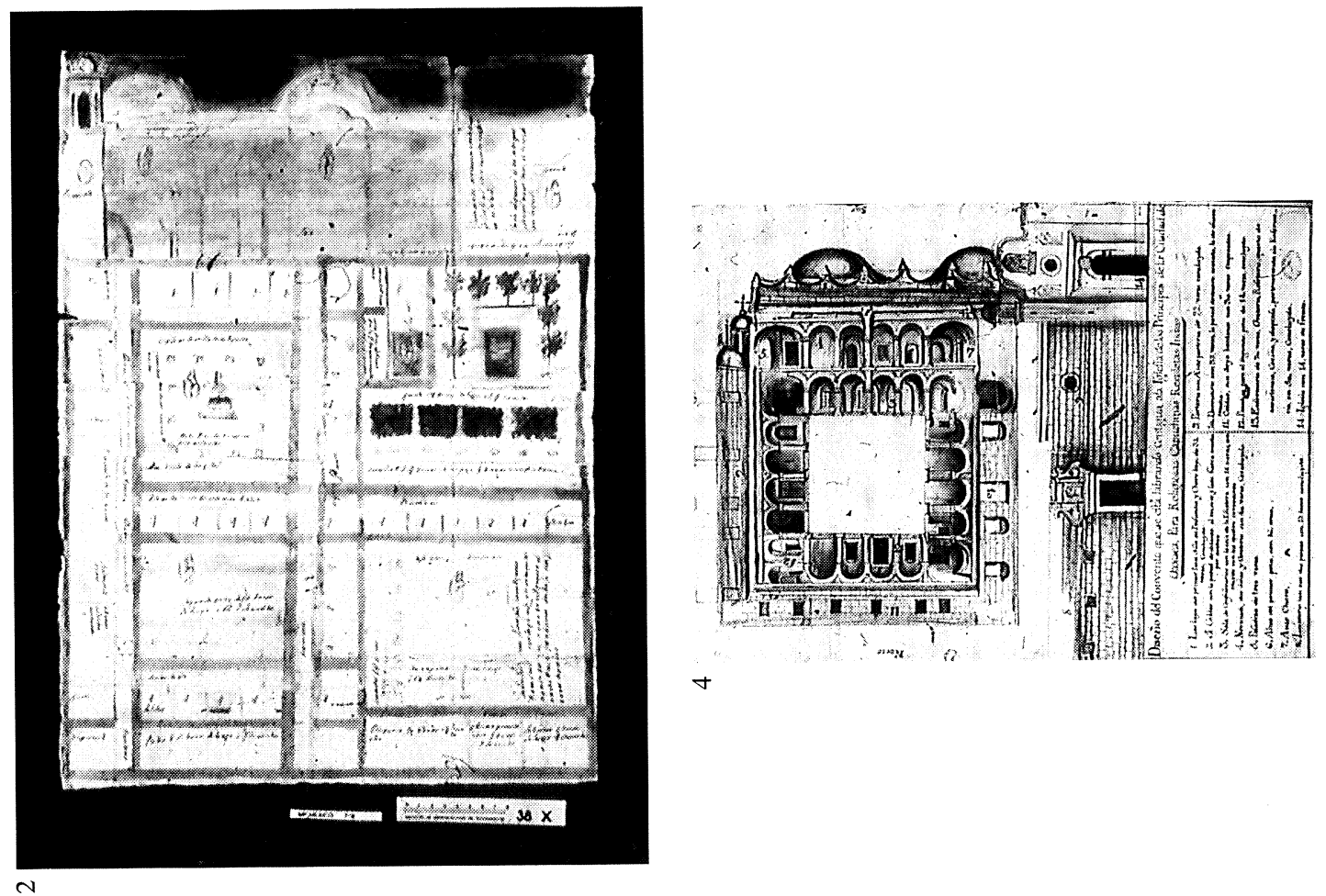

$\checkmark$
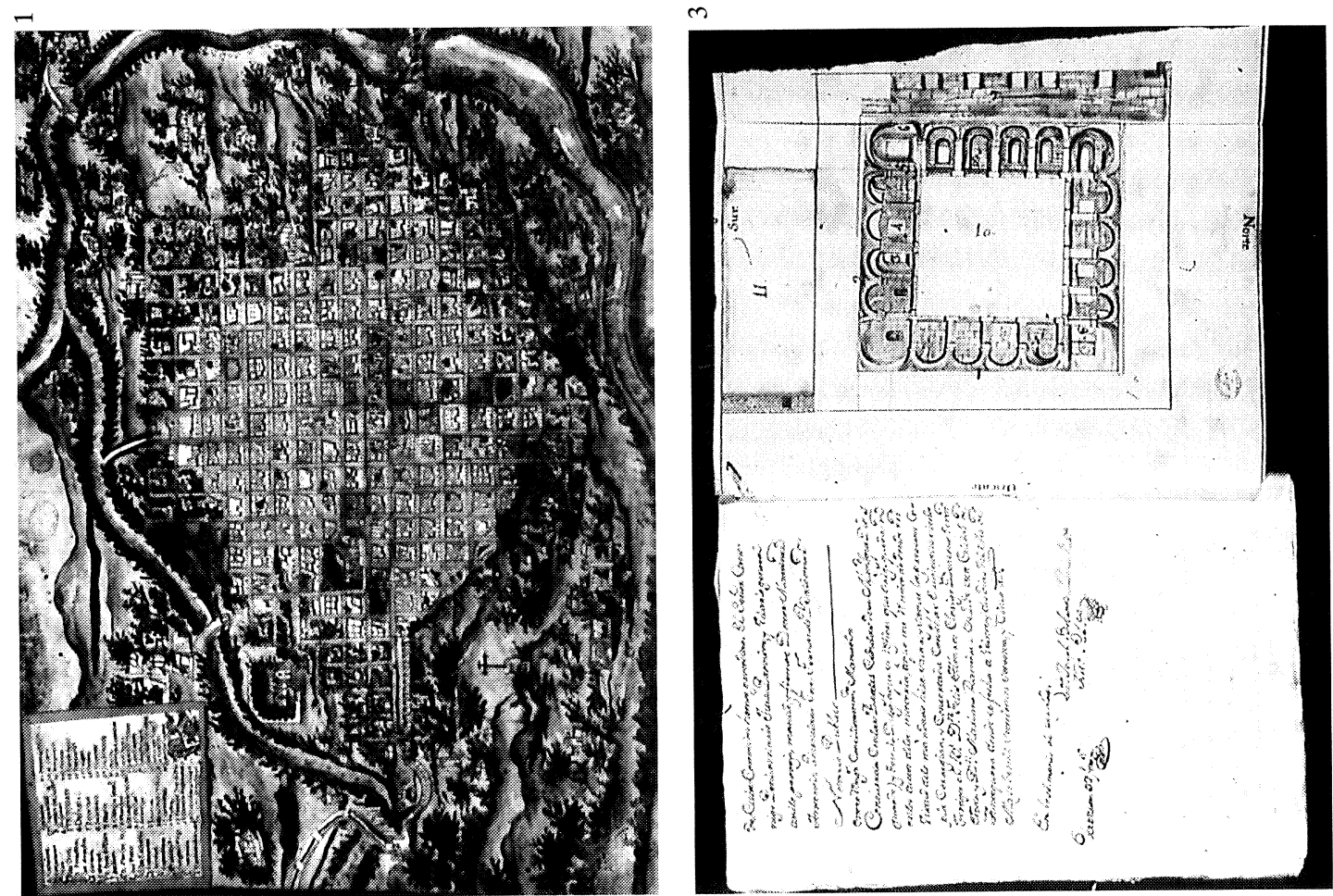

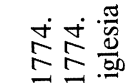

ㅎํㅇㅇㅛ

总《

爱

웡 웅

论

응 킁

ते

ปึ లే

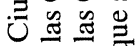

ชี के क

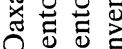

记

눙

ब ग

옳웡

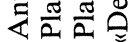

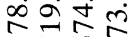

1.

运这

$\sum \sum \sum \Sigma$

过灾安

$\dot{\sim} \dot{\sim} \dot{r}$

$\sin$ 
te por lo que podían quedar las viviendas y claustro de las religiosas al lado izquierdo de la iglesia para tener más luz y en el lado derecho las casas de los capellanes y familiares" ${ }^{13}$, Intervinieron como patrocinadores de la obra don José Morillo y don Francisco de Quintas al ceder unos solares vecinos a la iglesia para fabricar el convento (Fig. 2).

Se le encargó a Felipe de Ureña la realización de la planta y diseño del nuevo edificio. Las obras comenzaron hacia 1767-68. Existen tres planos del futuro convento. En el primero aparece una edificación de grandes proporciones constituida por tres patios y una huerta. E1 patio principal situado junto a la iglesia, que marcó la orientación y el eje pues existía desde el siglo XVI, está centrado por un fuente; el segundo patio medía dieciséis varas de largo por doce de ancho y el tercero dieciocho varas de ancho. Alrededor de estos patios estaban dispuestas las celdas y las zonas conventuales comunes ${ }^{14}$. El segundo plano contiene la sección de uno de los patios del edificio formado por cuatro arcos de medio punto en cada lado apoyados sobre pilastras ${ }^{15}$ (Fig. 3). Por último, el tercer plano nos muestra la sección del patio principal o claustro, cuadrado y adosado a la iglesia, de proporciones similares al anterior. El patio está formado por cuatro arcos de medio punto que descansan sobre potentes columnas dóricas. En dos de sus lados, la columna de enmedio está dividida, descansando sobre una pilastra que continua en el piso superior. Una ondulante crestería barroca remata el eje adosado a la iglesia. La fachada de la iglesia presenta un arco de medio punto con potente dovela y entablamento sobre el que se coloca un óculo y una hornacina. A ambos lados del óculo se sitúan dos relieves de santos, rematándose en una forma ondulada. Una pequeña torre se haya situada en su lado izquierdo. En el plano se apreciar, asimismo, la portada del convento formada por un dintel con potente cornisa decorado con rombos y rosetas en cuya clave se encuentra el emblema franciscano y sobre el que descansa una hornacina con la imagen de San Francisco entre columnas corintias, rematada por una cruz y rodeada por unos roleos.

\section{Documento $1 .^{\circ}$}

\section{AGI. MAP-673}

«Diseño del convento que se está labrando contiguo a la Iglesia de los Príncipes de la ciudad de Oaxaca para religiosas capuchinas recoletas indias:

1. Los bajos del primer patio, sala de Profundis y choro bajo de 32 varas concluidos.

2. Cinco celdas con la pared de delante al recibir y la de fuera media por acabar.

3. Sala de confesionarios con la caja de la escalera con 18 varas concluido con los cuatro corredores.

4. Noviciado, dos salas y oratorio con 40 varas. Concluido.

5. Pasadizo de tres varas.

6. Altos del primer patio con 16 arcos.

7. Ante choro.

8. Locutorio con sus dos piezas con 19 varas concluido.

9. Portería con anteportería de 22 varas concluido.

10. Dormitorio con 22 varas, la pared de dentro acabada, la de fuera media.

11. Celdas con seis ventanas con 30 varas empezadas.

12. Pasadizo para el segundo patio de 14 varas concluido.

13. Enfermería de 12 varas, oratorio, refetorio, quarto de asistencia, cocina y dispensa, perteneciente a la enfermería en 50 varas concluida.

14. Iglesia con 14 varas de frente».

13 AGI. México 2661. 24 de Septiembre de 1767.

14 AGI. MAP-719. Plano del convento de las Capuchinas de Oaxaca.

15 AGI, MAP-674. Plano del convento de las Capuchinas de Oaxaca. 


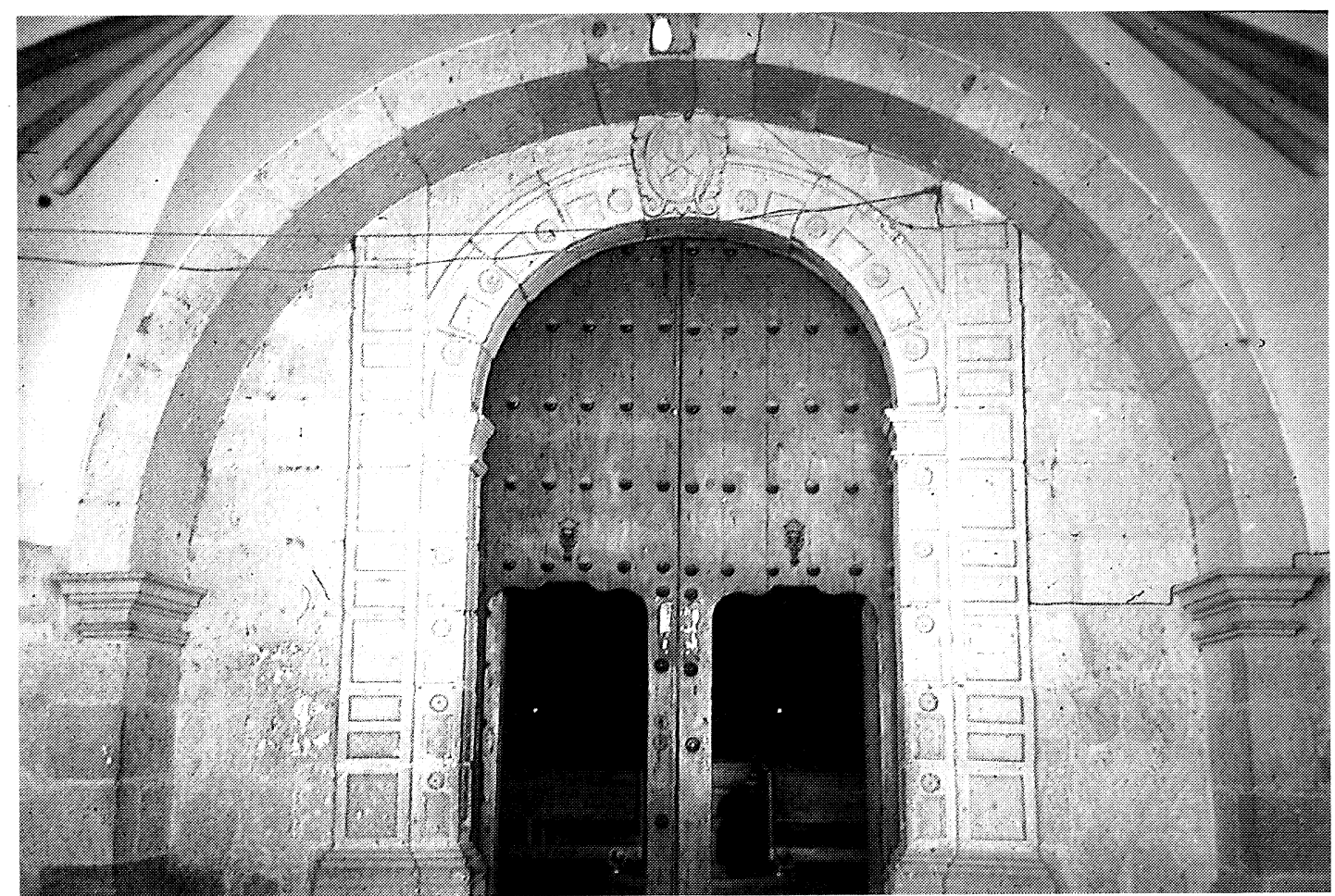

Fig. 5. Atrio y entrada a la iglesia de los Siete Príncipes.

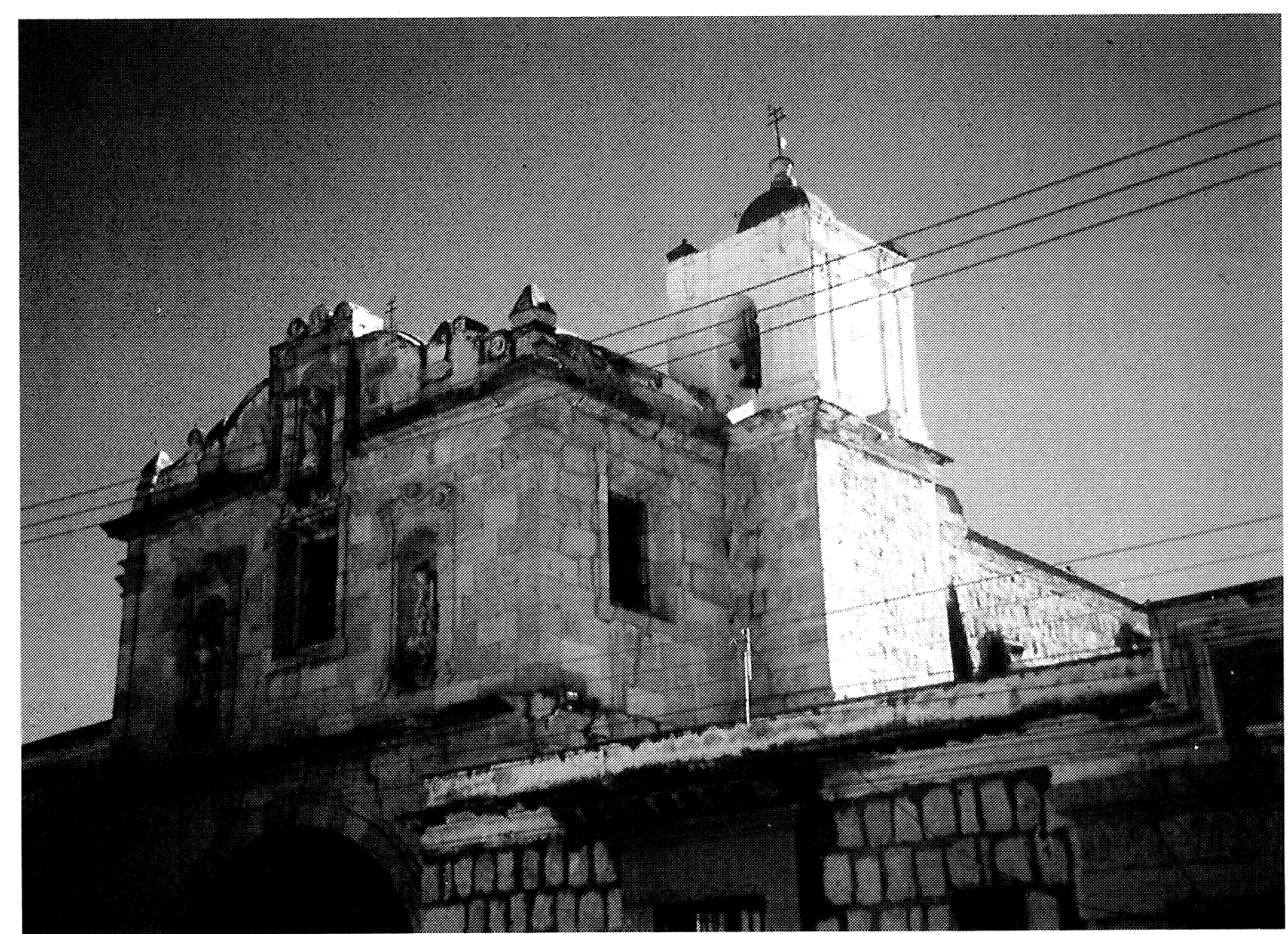

Fig. 6. Detalle de la torre y parte superior de la fachada de la iglesia de los Siete Príncipes. 
La decoración de la fachada de la iglesia y la del convento aunque se encuentran definidas dentro de una estilística barroca están lejos de la ornamentación de estípites utilizados por Ureña en las iglesias de Guanajuato o Aguascalientes. Se trata de una decoración barroca pero sobria aunque novedosa en cuanto al peculiar estilo artístico oaxaqueño muy característico y similar en las fachadas de sus iglesias y cuyo origen parece inevitable relacionarlo con los dominicos a cuyo cargo estuvo la evangelización de la zona y que se empieza a sentir en la fachada de Cloixtlahuaca levantada hacia $1576{ }^{16}$ (Fig. 4). La fachada del convento es la misma que proyectó Ureña tal como puede cotejarse con el plano existente; no sucede lo mismo con la de la iglesia. Sabemos que cuando se proyectó el convento existía una capilla dedicada a los Siete Príncipes sin embargo en la documentación encontrada se determina que la iglesia se hizo de nueva planta y que su coste había sido muy elevado. El proyecto de Ureña presenta la fachada del convento y de la iglesia en un solo plano; sin embargo, en la actualidad, la fachada de la iglesia avanza mediante un pequeño atrio compuesto por un arco de medio punto abovedado construido posteriormente para ampliar el coro. Este agregado puede comprobarse al examinar las jambas de la puerta de la iglesia que se pierden en le muro sin ninguna solución de continuidad así como en la mutilación del escudo situado en la clave del arco, emblema de los arcángeles. Se trata, una vez más en Oaxaca, de una fachada "sobrepuesta» a otra anterior existente copiándole algunos de sus rasgos y aprovechando las imágenes existentes en las hornacina ${ }^{17}$.

En Septiembre de 1769 se hallaban gastado en la obra más de 62.500 pesos a los que había que añadir los 1.626 de materiales; esta cantidad especificaba que había sido más costosa la reedificación de la iglesia y su ornato que el resto del edificio, aún sin terminar, para el que bastarían 12.000 pesos más para finalizarlo. Sin embargo, el 25 de Noviembre de 1774, don Diego de Villasante y don Antonio de la Vega, regidores de la ciudad de Oaxaca, emitieron un informe donde se incluía la valoración del costo del convento realizada por Felipe de Ureña, maestro de arquitectura y autor de la traza (Fig. 5).

\section{Documento $2 .^{\circ}$}

AGI. México 2661

«Digo yo el maestro de arquitectura, carpintería ensamblaje que por orden de D. Diego Villasante y D. Antonio de la Vega pase a la iglesia de los Siete Príncipes a ver y reconocer 1a obra del convento y digo lo siguiente: Lo fabricado del convento es el claustro o primer patio es de treinta varas en quadro netas conclusos corredores, los que están acabados en lo bajo y todas las piezas de su contorno están acabadas cubiertas de bóvedas que se componen y que son: en la frente está la portería y anteportería, dos piezas en 1a reja y otra pieza para ropería sigue al lado izquierdo la enfermería de treinta varas y otras tres piezas que son refectorio, pieza de asistencia y un pasadizo todas acabadas; al lado derecho este el coro bajo, una sala capaz para los confesionarios y la escalera y en la otra frente opuesto a la portería esta 1a sala de Profundis. Todo lo dicho tocante a lo bajo esta acabado por lo que toca a bóveda y techados los corredores. En lo alto está acabado el noviciado, la caja de la escalera y el antecoro, ya cubierto de azotea, el dormitorio está a medias paredes y algunas celdas principiadas. El segundo patio está con todos los arreos para los corredores, en este esta el refectorio ya cubierto de bóveda es de veinte varas; hay otras piezas capaces, otra escalera necesaria y un portal grande para lavadero todo este en estado de recibir bóvedas, todas las paredes maestras tienen de grueso vara y tercia; hay existentes para proseguir la obra cantidad de materiales como son ladrillo, cal, piedra y madera; de todo tengo hecha regulación por menor. Vale toda la fabrica 25.000 pesos. De las tres partes de la obra están hechas las dos falta una, esta se acabara en 10.000 pasos mas o menos porque hay anchos materiales en ser. El

${ }^{16}$ Berlin, Heinrich: "Oaxaca: San Felipe Neri. Noticias de artífices», en Archivo Español de Arte, n. ${ }^{\circ} 221$, Madrid, 1983, pág. 49.

17 Cervantes, Enrique A.: «Templo y Convento de los Siete Príncipes», en Nuestro México, t. I, n. ${ }^{\circ} 2$. 

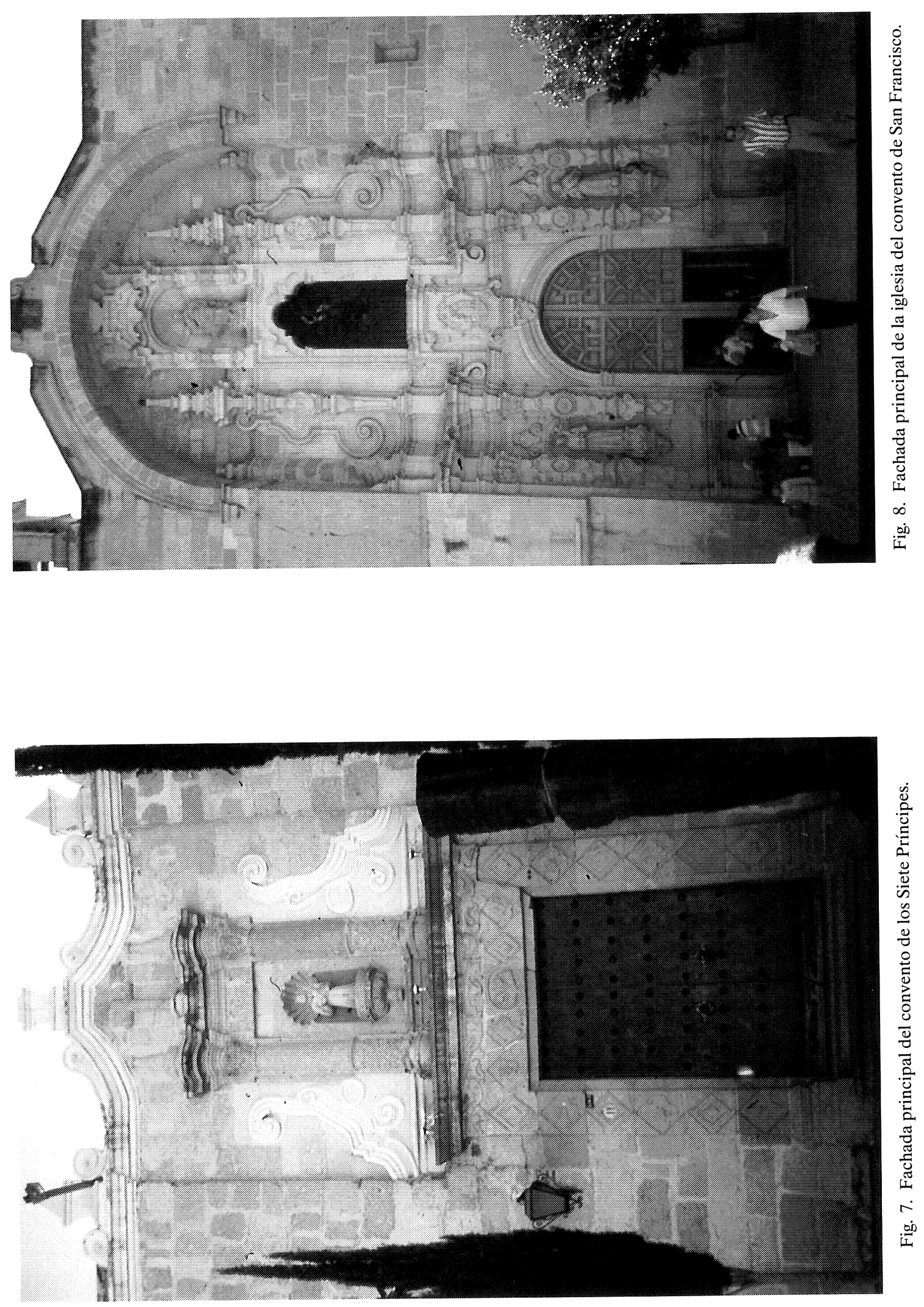
sitio en que esta es una quadra entera que se compone de 100 varas en quadro reducidas a varas cubicas, producen la cantidad de 10.000 varas que al precio de dos reales cada vara monta la cantidad de 2.500 pesos. Goza de buen terreno sin humedad pues el agua no se encuentra hasta diez o doce varas, tierra firme y fertil que promete sanidad y comodidades para la vida humana. La iglesia esta al lado derecho del convento, esta fabricada en el mediano de la quadra con puerta al Poniente, es de bóveda con buena simetría y buenas paredes son quarenta varas exclusas las paredes, su ancho diez varas, torre correspondiente con las campanas suficientes, esta adornada de altares el mayor y cuatro laterales todos nuevos y dorados. Vale 35.000 pesos. 5 de Septiembre de 1774. Firmado: Phelipe de Ureña».

Como director del proyecto y de la obra informó que estaba acabado el primer cuerpo del edificio, cubierto de bóvedas y hechas las paredes de los altos del primer patio del que sólo faltaban los tabiques y pilares de los corredores y sus cubiertas. El segundo patio estaba acabado todo su primer cuerpo, hechos los corredores de arquería y cubiertas las habitaciones. La obra del convento estaba finalizada en sus dos tercios. La iglesia, situada a la derecha del edificio, se construyó de nueva planta, hallándose acabada y adornada con un retablo mayor y cuatro retablos laterales dispuestos en su única nave, todos nuevos y dorados. No hay pruebas de que el autor de los retablos fuese Ureña pero dada su maestría como carpintero y ensamblador cabe la posibilidad que el ornato de la iglesia lo hubiese proyectado y realizado él mismo.

Veinte años más tarde, en 1794, se acomete una nueva obra en el convento. El obispo de Oaxaca D. José Gregorio Alonso de Ortigosa dispuso que del excedente de las rentas del obispado se destinasen seis mil pesos a dar nueva forma y consolidar las celdas con la cláusula que de hacer lo contrario revocaba la donación. La restauración debía consistir en lo siguiente: las celdas que estaban orientadas al sur y tomaban la luz del corredor se habían de retirar hacia el norte y servir de ambulatorio y pasadizo, dándoles a las celdas y al pasadizo las luces correspondientes. Las nuevas celdas que se iban a fabricar partirían desde el dormitorio común orientado a poniente y continuarían sobre el corredor que mira al sur «fabricando sobre bóveda las que se puedan» ${ }^{18}$. Debían fortificarse los pilares del patio para asegurar las celdas construidas sobre el corredor recibiendo sobre arcos de pilar a pilar los tabiques que hacían la división de los cuartos y por último el tránsito para el coro se haría, a partir de entonces, por el antiguo dormitorio mientras que el dormitorio se destinaría a sala de labor (Figs. 6 y 7 ).

La otra gran obra acometida por Felipe de Ureña en Oaxaca fue la construcción del convento de San Francisco. Los franciscanos junto a los dominicos y agustinos constituyeron las primeras órdenes religiosas que se establecieron en Oaxaca tras la llegada de los españoles. El convento lo fabricaron en las postrimerías del siglo xvi junto a la ermita de San Ildefonso. Uno de los principales legos fue Fr. Manuel de Jesús (1544-1634) que participó activamente en la construcción del edificio recolectando abundantes limosnas para su obra "viendo terminado el templo y aun le alcanzaron los recursos para enriquecer con ornamentos la sacristía y edificar una parte del convento grande» ${ }^{19}$. Por una relación de las iglesias y conventos de la ciudad de Oaxaca dada por su Obispo en 1590 se comprueba la existencia del convento de San Francisco donde se menciona como «una iglesia y casa de común y ordinario" pero se indicaba que poseía mas plata que el convento de Santo Domingo ${ }^{20}$. En 1667, el canónigo de la catedral Miguel Araujo y Figueroa en la fuerte discusión sobre las bóvedas de la catedral pone de ejemplo la iglesia de San Francisco como «deficientemente abovedada" porque la nave del coro estaba próxima a derrumbarse ${ }^{21}$. Es posible que tras

\footnotetext{
18 AGNEO. Protocolo de José Alvarez. 24 de Julio de 1794.

19 GAY, José Antonio: Historia de Oaxaca, Editorial Porrúa. Tercera Edición. México 1990, pág. 347.

20 AGI. México 357. Relación de iglesias, conventos y ermitas que hay en la ciudad de Antequera dada por el Obispo en 24 de Abril de 1990 por orden del Rey.

${ }^{21}$ Mullen, Robert J.: La arquitectura y la escultura de Oaxaca. 1530-1980. Tule. México, 1992, pág. 89.
} 

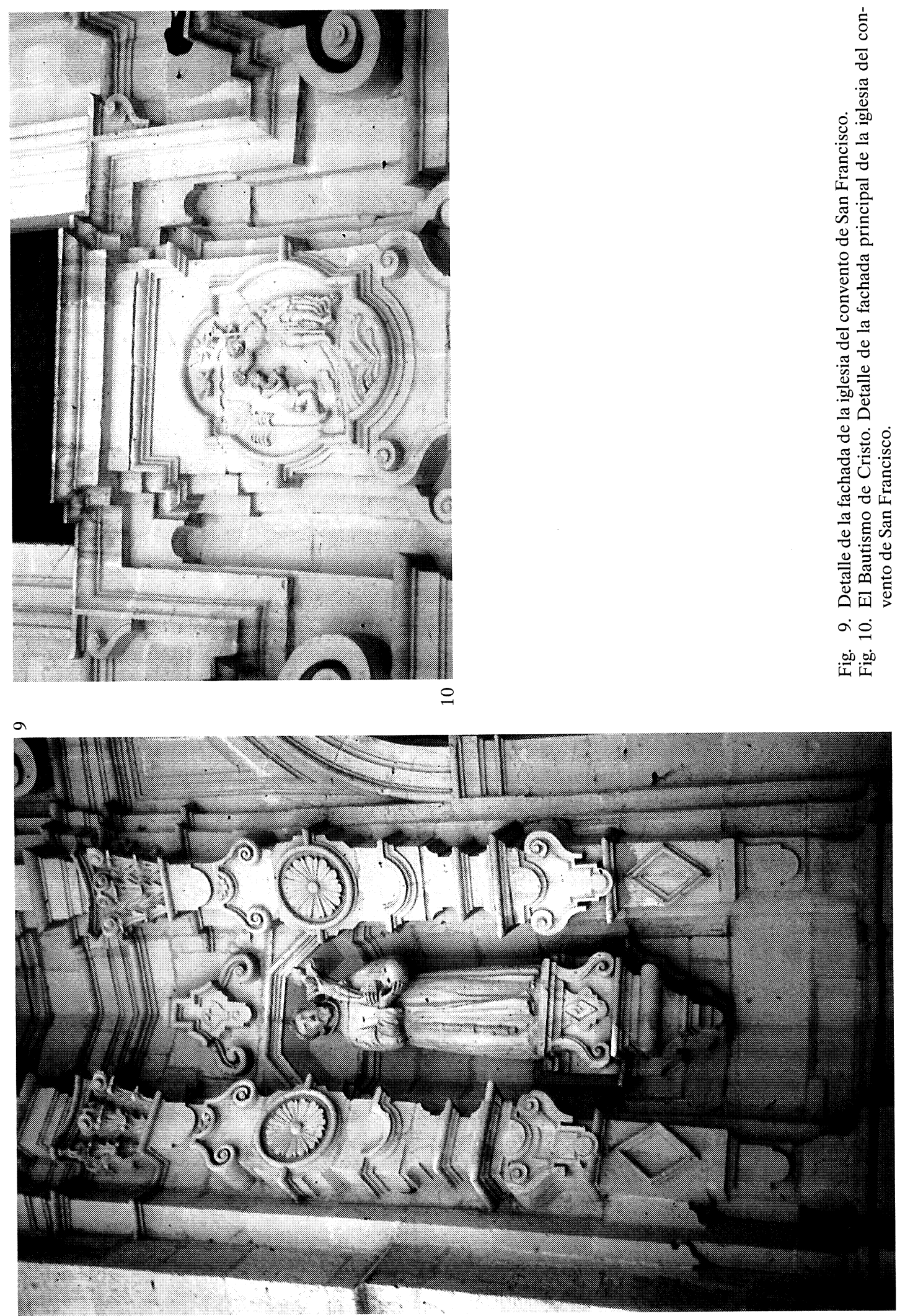
los fuertes temblores sufridos en la ciudad las bóvedas sufrieran un grave deterioro sin embargo las obras de reconstrucción no se realizaron hasta $1766^{22}$.

En 1766 comienza la reconstrucción de la iglesia y la obra de la portada que estará dirigida por Felipe de Ureña. Su intervención no se limitaría a la arquitectura como veremos a continuación. Los primeros pagos tanto a Ureña, "maestro maior por haber regentado la obra", como a los demás oficiales comenzaron el 6 de Abril de aquel año, se trataba de unos pagos periódicos que finalizaron en 1770. Por ellos se deduce que la obra consistió en cerrar las bóvedas del crucero donde se encontraba el altar de San Pedro de Alcántara, más otras dos bóvedas perteneciente una de ellas a la capilla de Ntra. Sra. de la Concepción así como terminar el cimborrio. Dentro las obras de menor envergadura que se acometieron cabe mencionar la nueva pila de la sacristía y una pileta para el agua bendita del coro (Fig. 8).

La construcción más novedosa de Felipe de Ureña en Oaxaca fue el proyecto y dirección de la portada de la iglesia cuyo costo total ascendió a 12.362 pesos ${ }^{23}$. Hay que tener en cuenta que junto al templo principal, formando un ángulo de 90 grados, existía la capilla de la Tercera Orden levantada en 1733 cuya fachada barroca dista mucho de las novedades arquitectónicas que iba a introducir Ureña ${ }^{24}$. La portada está inscrita dentro de un gran arco abocinado, con una suave curvatura cóncava y presenta característicos estípites dentro de una alteración de los órdenes arquitectónicos. El dinamismo de su planta rompe la impresión de frontalidad de la fachada en una disposición sesgada, que unido a la utilización del estípite con su fuste formado por la pirámide troncocónica invertida, diversos cuerpos superpuestos con medallones y roleos y las imágenes de los santos Francisco y Diego de Alcántara en los interestípites la convierten en excepcional y única dentro de la panorámica artística oaxaqueña. Presenta tres cuerpos, el primero formado por un gran arco de medio punto que da acceso al templo flanqueado por una pareja de estípites entre los cuales se hallan las imágenes aludidas anteriormente. El segundo cuerpo descansa sobre una potente cornisa centralizada por un medallón con la representación del Bautismo de Jesucristo y está configurado por una ventana de arco polilobulado entre una pareja de estípites con medallones alusivos a la orden franciscana. El remate está formado por una hornacina con la imagen de la Virgen María entre pilastras adornadas con rosetones y voluminosos chapiteles que sirven de remate a los estípites del segundo cuerpo (Fig. 9).

El trabajo de Felipe de Ureña en San Francisco no estuvo limitado a obras de arquitectura sino que también intervino como retablista y maestro de carpintería. Como retablista "puso" ocho colaterales: el retablo mayor, el de la Purificación, el de San Pedro de Alcántara, dos dedicados a San José, dos dedicados a San Francisco y uno a San Antonio. Además realizó obras de menor envergadura tales como puertas, barandales para el comulgatorio, atriles, un tabernáculo para la Virgen que estaba en el coro y un bastidor para ampliar el colateral que estaba dedicado a la Inmaculada. Trabajó ayudado por ocho oficiales durante cuatro meses y cobró 421 pesos.

\section{Documento $3 .^{\circ}$}

AGEO. Legajo 19. Exp. 22. Obispado 1766. Cuenta de recibo y gasto de la abra de la iglesia de Ntro., Padre San Francisco. Año 1772:

"Al maestro D. Phelipe de Ureña que habiéndose hecho cargo de lo restante de la obra trabajo dentro del convento lo siguiente con ocho oficiales que tuvo de asistentes por espacio de cuatro meses primeramente cinco pares de puertas para la sacristía, el portón de gracia., un par de ellas que salen al claustro, otros dos pares para la capilla de los Dolores, una hermosa pieza de tri-

22 AGEO. Legajo 19. Exp. 22 . 0bispado 1766. Cuenta de recibo y gasto de la obra de la iglesia de Ntro. Padre San Francisco. Año 1766.

23 Idem.

24 Ortiz Lajous, Jaime: Oaxaca. Tesoros del Centro Histórico. México, 1991, pág. 80. 
buna con siete varas de largo y una vara de ancho, un varandal para el comulgatorio se armaron y reforzaron los cajones de los ornamentos de la sacristía. Puso ocho colaterales es a saber el mayor el de la Purificación, San Pedro de Alcántara, dos chicos del Ssmo. Patriarca y de Ntro. Padre San Francisco y otros dos de N.P. y Sr. San Antonio fuera de la reja con el de Maria Santísima de los Dolores en la capilla. Echo una moldura de madera sobre la reja de fierro del antepecho del coro, compuso la reja de la iglesia echándole algunas piezas de moldura que le faltaban y el pulpito lo recorto en conformidad que pudiera quedar en la conformidad que hoy se mira. Hizo cinco atriles nuevos para los altares que no tenían, recorto las puertas de la iglesia que dividen la Tercera Orden por haberse levantado el piso, puso el tabernáculo de la Stma. Virgen que se venera sobre la reja del coro en donde puso también el facistol. Habiendo crecido el antiguo sitio en que estaba el colateral de Ntra. M. Ssma. de la Concepcion hizo dos bastidores de a seis vares de alto y media de ancho pera que igualase con las dos partes laterales y pintadas de amarillo fingio diestramente el dorado que le dio el pintor todo lo cual costeo el Sr. D. Pedro Iturribarria, hizo dos ramilletes de madera para el coro. Ultimamente hizo cuarenta y seis bastidores de todos tamaños para la iglesia, coro, sacristía, capilla y lanternillas para lo que se mantuvo en el convento y se le administraron cuatrocientos veintiún pesos como los fue pidiendo. Año 1772».

Las dos obras de Ureña en Oaxaca, el convento de los Siete Príncipes y el de San Francisco, aunque diferentes en su estilo constituyeron una novedad tanto desde el punto de vista artístico como personal del artista. En el convento de los Siete Principes se enfrentó a una gran obra arquitectónica que debía adaptar a unas necesidades determinadas y demostrar sus conocimientos de arquitectura conventual. Aunque no consta su intervención como retablista es muy posible que trazara los retablos pues no se conocen los nombres de otros carpinteros que trabajasen con él. En el convento de San Francisco trabaja como arquitecto y retablista introduciendo el estípite en la fachada por primera vez en la ciudad. Este hecho aislado, pues no se conocen otros ejemplos, fue sin duda innovador en cuanto a la utilización del estípite como parte de un sistema de orden arquitectónico aunque no se desarrollase posteriormente (Fig. 10).

La personalidad de Felipe de Ureña como la de otros arquitectos retablistas de Nueva España dista mucho de la imagen de ensambladores artesanos pertenecientes a anticuados gremios. Sus obras arquitectónicas muestran un vasto conocimiento de tratados de arquitectura de la época así como una destreza en el dibujo geométrico y la aritmética que lo elevan a la categoría de un artista instruido y culto. Sus comienzos como retablista no fueron impedimento para desarrollar actividades arquitectónicas fuera de la ciudad de México. El conocimiento de los trabajos de Jerónimo de Balbás y, posiblemente de Lorenzo Rodríguez, influyó de manera decisiva en llevar la retablística a la arquitectura realizando para la ciudades norteñas unas fachadas-retablos introduciendo el estípite como soporte arquitectónico. Esta tipología de fachada la llevó a Oaxaca lo que supuso un rompimiento dentro de los tradicionales modelos de portada existentes en la ciudad.

AGI. Archivo General de Indias.

AGNEO. Archivo General de Notarias del Estado de Oaxaca.

AGEO. Archivo General del Estado de Oaxaca. 